\title{
OX4OL GENE POLYMORPHISM AND BREAST CANCER IN IRANIAN POPULATION
}

\author{
R. Vakil Monfared, F. Mashayekhi* \\ Department of Biology, Faculty of Sciences, University of Guilan, Rasht 4193833697, Iran
}

\begin{abstract}
Background and Aim: The immune system plays an important role in the breast cancer development. OX40L (also known as TNFSF4), a membrane protein, which is a member of the tumor necrosis factor super family binds to its receptor OX40 and this co-stimulation has a crucial role in $\mathrm{T}$ cell proliferation, survival and cytokine release. Previous studies have shown that $O X 40 \mathrm{~L}$ is associated with cancer. Due to the importance of the T cells in antitumor activities of $O X 40 L$ we studied the association of $r s 3850641(A \rightarrow G)$ polymorphism of $O X 40 L$ gene with the breast cancer. Materials and Methods: The study included 123 women with breast cancer and 126 healthy volunteers with no signs of cancer. Genomic DNA was extracted from blood leucocytes. Genotype and allele frequencies were determined in patients and control cases with the method of polymerase chain reaction-restriction fragment length polymorphism and the statistical analysis was performed by Med Calc. Results: The prevalence of genotype frequencies of AA/

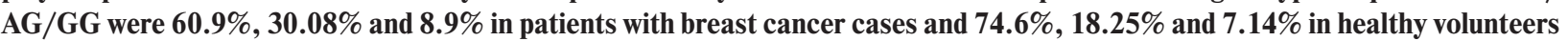
while the $A$ and $G$ allelic frequency was $\mathbf{7 6 . 0 1}$ and $23.98 \%$ in patients and 83.73 and $\mathbf{1 6 . 2 6 \%}$ in healthy controls, respectively. Statistical analysis has shown significant difference from the comparison of genotype $(p=0.03)$. Conclusion: It is concluded that the rs3850641 SNP is significantly associated with the breast cancer susceptibility in Iranian population. However, further studies in larger populations including other genetic and environmental factors are required to achieve conclusion.
\end{abstract}

Key Words: OX40L, gene polymorphism, breast cancer, PCR-RFLP.

Breast cancer is the most common invasive malignancy among women worldwide with an incidence reaching more than one million new cases [1]. Studies have indicated that the mean age of patients with breast cancer in Iran is approximately 10 years younger than in western countries [2]. Genetics and environmental factors have been shown to be important in breast cancer initiation and promotion. Many genes have been shown to have important roles in breast cancer onset, invasion, metastasis and prognosis. OX4OL which is also known as TNFSF4 and gp34 is a member of the tumor necrosis factor (TNF) super family and was first identified as gp34 on HTLV-I transformed cells [3]. OX40L is a type II glycoprotein which is located on the human chromosome 1 [4]. OX4OL is expressed on activated antigen presenting cells like B cells [5], dendritic cells [6] and macrophages [7] as well as natural killer cells (NK cells) [8], Langerhans cells [9], airway smooth muscle cells [10] and vascular endothelial cells [11]. OX4OL is also expressed on the surface of activated T cells which enhances further $T$ cell responses [12]. Its receptor OX40 is expressed on activated $\mathrm{T}$ cells and its ligation to $\mathrm{OX} 40 \mathrm{~L}$ promotes pathways which regulate the $T$ cell proliferation, effective activation, survival and cytokine release from the T cells [13]. Unlike OX40 expressing T cells, OX4OL expressing cells are only found in inflammatory sites and only those $T$ cells which migrate to inflammatory sites can receive the co-stimulatory effect of OX40L [7]. This prevents the widespread activation of OX40 on ac-

Submitted: March 06, 2017.

*Correspondence: E-mail: mashayekhi@guilan.ac.ir Abbreviations used: NF-KB - nuclear factor kappa-B; NK - natural killer; PCR - polymerase chain reaction; SLE - systemic lupus erythematosus; TNF - tumor necrosis factor; Tregs - regulatory T cells. tivated T cells [14]. OX40 stimulation results in IL-2R expression and IL-2 production which affects the T cell survival and effector differentiation through downstream molecules like nuclear factor kappa-B (NF-kB) and survivin [15]. The ligation of OX40 leads to the activation of the NF-KB by TRAF-2 induction which promotes the transcription of the target genes [16], and the activation of $\mathrm{PI}-3 \mathrm{~K}$ and protein kinase $\mathrm{B}$ (also known as AKT activation) [17]. The activation of Akt results in the expressing anti-apoptotic molecules like $\mathrm{BCl}-2$ and $\mathrm{Bcl}-\mathrm{xl}$ [18].

The anti-apoptotic protein survivin which is activated by an AKT/PKB-dependent activation increases the survival of the activated T cell, which leads to the increase of T cell clonal expansion [19]. OX40 stimulation leads to enhanced CD8 T cell differentiation against soluble or tumor associated antigen, which results in the increased expression of CD25 and granzyme $B$ expression and enhanced cytolytic activity [20] and also the accumulation of CD8 at the tumor site [21].

It has been shown that $O X 40 L$ polymorphisms are associated with diseases like systemic lupus erythematosus (SLE) [22] and systemic sclerosis [23]. Some studies have shown that OX40L fusion protein inhibited the growth of mouse 4T1 breast tumor model [24]. The OX40L rs3850641SNP is located at intron 1 of the OX40L. Variants in the intron of a gene may influence its expression and regulate its function. In this study we aimed to determine the association of the OX4OL polymorphism with breast cancer in Iran.

\section{MATERIALS AND METHODS}

Blood samples were collected from a total of 123 patients with sporadic breast cancer and 126 healthy blood donors as control cases with no signs of any cancer. The study has been approved 
by the appropriate ethics committee and have been performed in accordance with the ethical standards laid down in the 1964 Declaration of Helsinki and its later amendments. All persons gave their informed consent prior to their inclusion in the study.

We extracted the genomic DNA from blood cells by using Gpp Solution DNA extraction kit (Genpajoohan, Iran), Chloroform, $90 \%$ and $70 \%$ ethanol and $\mathrm{NaCl}$. The target genes OX4OL, with a 769 base pair length, was amplified by using forward and reverse primers (Table 1) (Generay, China) by polymerase chain reaction (PCR). The PCR mixture contained $10 \mu \mathrm{l}$ Master mix, $1 \mu \mathrm{l}$ of each primer, $5 \mu$ l template DNA and $3 \mu$ ldeionized water. Amplification was performed as followed: denaturation for $5 \mathrm{~min}$ at $95^{\circ} \mathrm{C}$ and 35 cycles with the program $95^{\circ} \mathrm{C}$ in $45 \mathrm{~s}$, annealing temperature $55^{\circ} \mathrm{C}$ for $45 \mathrm{~s}, 72^{\circ} \mathrm{C}$ for $45 \mathrm{~s}$ and finally $72^{\circ} \mathrm{C}$ for $5 \mathrm{~min}$ to ensure the product extension.

Table 1. Forward and reverse primer designation used in amplification

\begin{tabular}{lcc}
\hline \multicolumn{1}{c}{ Primer designation } & Primer sequences & Length \\
\hline Forward & $5^{\prime}$-TCTTATGCCAAAAGTGTTGAGT-3' & 22bp \\
Reverse & $5^{\prime}$-TAGCTCAACAAAGGAACACGA-3' & 21bp \\
\hline
\end{tabular}

The PCR products were electrophoresed on $2 \%$ agarose gel and visualized by UV light. After being sure of having PCR products the products were digested by $\mathrm{HpyCH} 4 \mathrm{III}$ which cutes the DNA in the ACN*GT restriction site and the result is DNA fragments with the sizes of 769,521 , and 248 base pairs. The products were electrophoresed on $2 \%$ agarose gel (Figure).

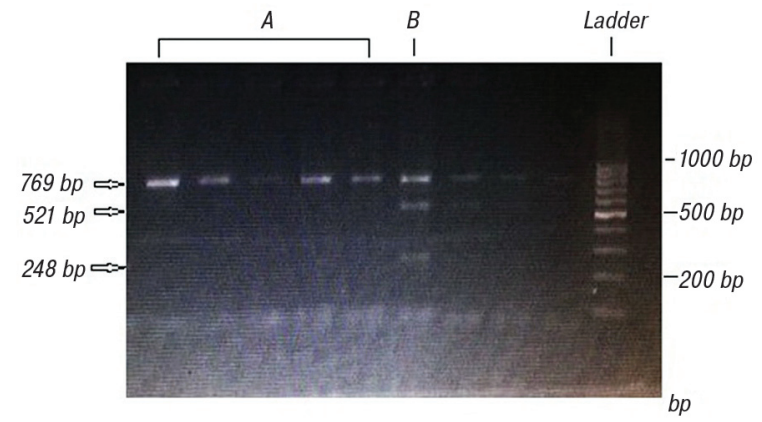

Figure. Agarose gel electrophoresis after the digestion of the DNA of the patient group by HpyCH4III. A 769bp segment represents $A / A$ homozygosis $(A)$ while 769,521 , and 248 base pairs represent $A / G$ Heterozygosis (B). Segments sized 521 and 248 represent $G / G$ mutant homozygosis

Statistical analysis. The statistical analysis was performed by MedCalc chi-square test (version 14.8.1) to make a comparison between genotypes and alleles. We used Hardy — Weinberg equilibrium (HWE) to evaluate deviation between observed and expected frequencies. A value of $p<0.05$ was considered statistically significant.

\section{RESULTS}

The study included 123 controls and 126 patients with breast cancer. The patients ranged in the age group from 20 to 80 years old, and the healthy controls aged from 20 to 70 years old. The PCR product had a 769 base pair length and the details of enzyme digestion are shown in Table 2. The Hardy - Weinberg analysis is shown in Table 3. Distribution of OX40L genotypes was incompatible with HWE for control group but not for breast cancer patients $(p=0.00082$ and $p=0.07$, respectively). Deviation from HWE can be caused by some reasons such as small number of subjects or random genetic drift. The allele and genotypes frequencies of the studied genetic variants in breast cancer cases and healthy subjects are shown in Table 4. The genotype frequencies of AA/AG/GG were $60.9 \%$, $30.08 \%$ and $8.9 \%$ in breast cancer cases and $74.6 \%$, $18.25 \%$ and $7.14 \%$ in healthy volunteers.

Table 2. Restriction fragment length polymorphism data of the restriction site of $\mathrm{HpyCH} 4 \mathrm{II}$ and the sizes of DNA fragments after digestion by this enzyme

\begin{tabular}{lcc}
\hline \multicolumn{1}{c}{ Enzyme } & HpyCH4IIII \\
\hline Restriction site & & $5^{\prime} \ldots$ ACNGT.... \\
& $3^{\prime}$...TGNCA...5 \\
Size of DNA segments & T/T genotype & $769 \mathrm{bp}$ \\
after digestion & T/C genotype & $769,521,248 \mathrm{bp}$ \\
& C/C genotype & $521,248 \mathrm{bp}$ \\
\hline
\end{tabular}

Table 3. Hardy - Weinberg analysis

\begin{tabular}{|c|c|c|c|c|c|c|}
\hline \multirow{2}{*}{ Subjects } & \multicolumn{3}{|c|}{ Genotypes } & \multicolumn{2}{|c|}{ Alleles } & \\
\hline & $\overline{A A}$ & $A G$ & $\mathrm{GG}$ & $A$ & $\mathrm{G}$ & \\
\hline Controls, n (\%) & $94(75)$ & $23(18)$ & $9(7)$ & 211 (84) & $41(16)$ & 0.00082 \\
\hline Patients, n (\%) & 75 (61) & $37(30)$ & $11(9)$ & $187(76)$ & 59 (24) & 0.07 \\
\hline
\end{tabular}

Table 4. Genotype and allele distributions of rs3850641 polymorphism

\begin{tabular}{lccccc}
\hline \multicolumn{1}{c}{$\begin{array}{c}\text { Genetic } \\
\text { models }\end{array}$} & $\begin{array}{c}\text { Geno- } \\
\text { types }\end{array}$ & $\begin{array}{c}\text { Controls, } \\
\mathrm{n}(\%)\end{array}$ & $\begin{array}{c}\text { Patients, } \\
\mathrm{n}(\%)\end{array}$ & OR $(95 \% \mathrm{Cl})$ & $p$ \\
\hline Codominant & $\mathrm{AA}$ & $94(74.6)$ & $75(61.0)$ & 1.00 & \\
& $\mathrm{AG}$ & $23(18.2)$ & $37(30.1)$ & $2.02(1.10-3.68)$ & 0.061 \\
& $\mathrm{GG}$ & $9(7.1)$ & $11(8.9)$ & $1.53(0.60-3.89)$ & \\
Dominant & $\mathrm{AA}$ & $94(74.6)$ & $75(61.0)$ & 1.00 & \\
& $\mathrm{AG}-\mathrm{GG}$ & $32(25.4)$ & $48(39.0)$ & $1.88(1.09-3.23)$ & 0.021 \\
Recessive & $\mathrm{AA}-\mathrm{AG}$ & $117(92.9)$ & $112(91.1)$ & 1.00 & \\
Overdominant & $\mathrm{GG}$ & $9(7.1)$ & $11(8.9)$ & $1.28(0.51-3.20)$ & 0.6 \\
& $\mathrm{AAG}$ & $103(81.8)$ & $86(69.9)$ & 1.00 & \\
Log-additive & $\mathrm{AG}$ & $23(18.2)$ & $37(30.1)$ & $1.93(1.06-3.49)$ & 0.029 \\
Alleles & $\mathrm{A}$ & $211(84.0)$ & $187(76.0)$ & 1.00 & \\
& $\mathrm{G}$ & $41(16.0)$ & $59(24.0)$ & $1.62(1.04-2.53)$ & 0.03 \\
\hline
\end{tabular}

The $A G$ and $G G$ genotypes of the polymorphism were seen in 48 patients with breast cancer (39.0\%) and 32 controls $(25.4 \%$ ) (dominant model: $\mathrm{OR}=1.88$; $95 \% \mathrm{Cl} 1.09-3.23 ; p=0.021$ ). The association was also significant when analyzing the AG genotype in overdominant model $(\mathrm{OR}=1.93 ; 95 \% \mathrm{Cl} 1.06-3.49 ; p=$ 0.029 ). The A allele frequency was $76.01 \%$ in patients and $83.73 \%$ in control groups. The prevalence of $\mathrm{G}$ allele was $23.98 \%$ in patients and $16.26 \%$ in the control group. The results show that there is a significant difference in the genotype and allele frequencies between two groups ( $p=0.04$ and $p=0.03$, respectively) (see Table 4).

\section{DISCUSSION}

The objective of this study was to examine the relationship between OX4OL rs3850641 polymorphism and breast cancer susceptibility in Iran. Result reveal that rs3850641 $\mathrm{G}$ allele is associated with a significantly higher risk of breast cancer.

Breast cancer is the most common invasive malignancy type worldwide. It is estimated that more than one million women are diagnosed with breast cancer and 450,000 cases die annually by this disease [1]. OX40L, a type 2 membrane protein, is a member of the 
TNF superfamily [5]. OX4OL is expressed by activated $B$ cells, vessel endothelial cells, macrophages, dendritic cells and certain activated T cells. This generates co-stimulatory signals by interacting with TNFRSF4 on activated T Iymphocytes and enhances the proliferation and differentiation of $\mathrm{T}$ Iymphocytes and the development and survival of memory T cells [25]. A study by Zaini et al. [26] has shown that TNF-a-stimulated dendritic cells maturation in mice was accompanied by increased expression of OX40 ligand (OX40L), the lack of which resulted in an inability of mature dendritic cells to generate cellular antitumor immunity. Furthermore, intratumoral administration of dendritic cells modified to express OX40L suppressed tumor growth through the generation of tumor-specific cytolytic T cell responses, which were mediated by CD4 T cells and NK T cells. In the tumors treated with OX40L-expressing dendritic cells, the NK T cell population significantly increased and exhibited a substantial level of IFN-y production essential for antitumor immunity. These results indicate that the OX40L expression on dendritic cells is crucial in the development of antitumor immunity, possibly by coupling innate to adaptive immunity [26].

The proliferation of naive CD8 T cells or previously activated $\mathrm{CD}^{+} \mathrm{T}$ cells were suppressed by regulatory T cells (Tregs), though not to the same extent as CD4 ${ }^{+}$ $T$ cells. Tregs suppressed the proliferation of naive $\mathrm{CD}^{+}$, naive $\mathrm{CD}^{+} \mathrm{T}$ and $\mathrm{CD} 25^{-} \mathrm{T}$ cells after TCR triggering, in contrast, OX40 co-stimulated Tregs that reduced Foxp3 expression reversed the suppressive function [27].

Studies have shown that OX4OL polymorphisms are associated with SLE [22]. Another study has shown the association of the OX4OL polymorphism in systemic sclerosis [23]. Polymorphisms of OX4OL are also associated with arthrosclerosis [28]. Other studies suggested that $O X 40 L$ polymorphism was associated with myocardial infarction [29]. Fu et al. [30] conducted a meta-analysis with 9 articles to assess the relationship between rs3850641 genetic polymorphisms and coronary heart disease. They found that rs3850641 was not associated with increased risk of coronary heart disease [30]. In agreement with this result, Lu et al. [31] reported that there is no main effect of $O X 40 \mathrm{~L}$ gene polymorphism on cerebrovascular and cardiovascular diseases risk. So far, only one case-control study of breast cancer and OX40L gene polymorphism has been carried out with 557 cases and 580 controls [32]. They found significant association between rs3850641 and breast cancer risk under the additive and dominant models $(p=0.01042$ and $p=0.01942$, respectively). Moreover, rs3850641G allele could increase the susceptibility to breast cancer $(p=0.009662)$.

It is found that in a mouse model of allergic asthma basophiles highly expressed OX40 ligand (OX40L) after activation. The results reveal a critical role of OX40L presented by the activated basophiles to initiate Th2 responses in an allergic asthma model, implicat- ing OX40-OX40L signaling as a potential therapeutic target in the treatment of allergic airway inflammation [12]. Blocking OX40-OX40L interaction has been considered an approach to the treatment of various diseases in which T cells play a critical role. In animal models, OX40L blockade in vivo has been shown to weaken harmful diseases in many inflammatory and autoimmune models like allergic asthma, colitis, diabetes, arthritis, atherosclerosis and allograft rejection. Evidences showed that inflammatory responses play a crucial role at different stages of tumor development and contributes to the initiation and progression of cancer [33].

It is concluded that the rs3850641 polymorphism is associated with the susceptibility of breast cancer in Iran. It is necessary to confirm this result with larger sample size in multiethnic groups in the future.

\section{ACKNOWLEDGEMENTS}

This study was supported by the University of Guilan.

\section{CONFLICT OF INTEREST}

The authors declare that there is no conflict of interest.

\section{REFERENCES}

1. Coughlin SS, Ekwueme DU. Breast cancer as a global health concern. Cancer Epidemiol 2009; 33: 315-8.

2. Ebrahimi M, Vahdaninia M, Montazeri A. Risk factors for breast cancer in Iran: a case-control study. Breast Cancer Res 2002; 4: 12-6.

3. Compaan DM, Hymowitz SG. The crystal structure of the costimulatory OX40-OX40L complex. Structure 2006; 14: $1321-30$.

4. Miura S, Ohtani K, Numata N, et al. Molecular cloning and characterization of a novel glycoprotein, gp34, that is specifically induced by the human T-cell leukemia virus type I trans-activator p40tax. Mol Cell Biol 1991; 11: 1313-25.

5. Lee J, Dollins CM, Boczkowski D, et al. Activated B cells modified by electroporation of multiple mRNAs encoding immune stimulatory molecules are comparable to mature dendritic cells in inducing in vitro antigen-specific T-cell responses. Immunology 2008; 125: 229-40.

6. Ohshima Y, Tanaka Y, Tozawa H, et al. Expression and function of OX40 ligand on human dendritic cells. J Immunol 1997; 159: 3838-48.

7. Weinberg AD, Wegmann KW, Funatake C, et al. Blocking OX-40/OX-40 ligand interaction in vitro and in vivo leads to decreased $\mathrm{T}$ cell function and amelioration of experimental allergic encephalomyelitis. J Immunol 1999; 162: 1818-26.

8. Zingoni A, Sornasse T, Cocks BG, et al. Cross-talk between activated human NK cells and CD4+ T cells via OX40OX40 ligand interactions. J Immunol 2004; 173: 3716-24.

9. Sato T, Ishii N, Murata K, et al. Consequences of OX40OX40 ligand interactions in langerhans cell function: enhanced contact hypersensitivity responses in OX40L-transgenic mice. Eur J Immunol 2002; 32: 3326-35.

10. Burgess JK, Carlin S, Pack RA, et al. Detection and characterization of OX40 ligand expression in human airway smooth muscle cells: a possible role in asthma? J Allergy Clin Immunol 2004; 113: 683-9.

11. Imura A, Hori $T$, Imada $K$, et al. The human OX40/ gp34 system directly mediates adhesion of activated $\mathrm{T}$ cells to vascular endothelial cells. J Exp Med 1996; 183: 2185-95. 
12. Di C, Lin X, Zhang Y, et al. Basophil-associated OX40 ligand participates in the initiation of Th 2 responses during airway inflammation. J Biol Chem 2015; 290: 12523-36.

13. Reuter D, Staege MS, Kühnöl CD, et al. Immunostimulation by OX40 ligand transgenic Ewing sarcoma cells. Front Oncol 2015; 5: 242.

14. Redmond WL, Ruby CE, Weinberg AD. The role of OX40-mediated co-stimulation in T-cell activation and survival. Crit Rev Immunol 2009; 29: 187-201.

15. Lathrop SK, Huddleston CA, Dullforce PA, et al. A signal through OX40 (CD134) allows anergic, autoreactive $\mathrm{T}$ cells to acquire effector cell functions. J Immunol 2004; 172: 6735-43.

16. Kawamata $S$, Hori $T$, Imura $A$, et al. Activation of OX40 signal transduction pathways leads to tumor necrosis factor receptor-associated factor (TRAF) 2- and TRAF5-mediated NF-kappaB activation. J Biol Chem 1998; 273: 5808-14.

17. Mestas J, Crampton SP, Hori T, et al. Endothelial cell costimulation through OX40 augments and prolongs T-cell cytokine synthesis by stabilization of cytokine mRNA. Int Immunol 2005; 17: 737-47.

18. Rogers PR, Song J, Gramaglia I, et al. OX40 promotes $\mathrm{Bcl}-\mathrm{xL}$ and $\mathrm{Bcl}-2$ expression and is essential for long-term survival of CD4 T-cells. Immunity 2001; 15: 445-55.

19. Song J, Salek-Ardakani S, Rogers PR, et al. The costimulation regulated duration of $\mathrm{PKB}$ activation controls T cell longevity. Nat Immunol 2004; 5: 150-8.

20. Redmond WL, Weinberg AD. Targeting OX40 and OX40L for the treatment of autoimmunity and cancer. Crit Rev Immunol 2007; 27: 415-36.

21. Gough MJ, Ruby CE, Redmond WL, et al. OX40 agonist therapy enhances CD8 infiltration and decreases immune suppression in the tumor. Cancer Res 2008; 68: 5206-15.

22. Cunninghame Graham DS, Graham RR, et al. Polymorphism at the TNF superfamily gene TNFSF4 confers susceptibility to systemic lupus erythematosus. Nat Genet 2008; 40: 83-9.
23. Gourh P, Arnett FC, Tan FK, et al. Association of TNFSF4 (OX40L) polymorphisms with susceptibility to systemic sclerosis. Ann Rheum Dis 2010; 69: 550-5.

24. Ali SA, Ahmad M, Lynam J, et al. Anti-tumour therapeutic efficacy of OX40L in murine tumour model. Vaccine 2004; 22: 3585-94.

25. Weinberg AD. Ox40: targeted immunotherapy - implications for tempering autoimmunity and enhancing vaccines. Trends Immunol 2002; 23: 102-9.

26. Zaini J, Andarini S, Tahara M, et al. OX40 ligand expressed by DCs costimulates NKT and CD4+ Th cell antitumor immunity in mice. J Clin Invest 2007; 117: 3330-8.

27. Kitamura N, Murata S, Ueki T, et al. OX40 costimulation can abrogate Foxp3+ regulatory T cell-mediated suppression of antitumor immunity. Int J Cancer 2009; 125: 630-8.

28. Wang X, Ria M, Kelmenson PM, et al. Positional identification of TNFSF4, encoding OX40 ligand, as a gene that influences atherosclerosis susceptibility. Nat Genet 2005; 37: $365-72$.

29. Ria M, Lagercrantz J, Samnegård A, et al. A common polymorphism in the promoter region of the TNFSF4 gene is associated with lower allele-specific expression and risk of myocardial infarction. PLoS One 2011; 6: e17652.

30. Fu Y, Huang W, Jin D, et al. Association of TNFSF4 (rs3850641) gene polymorphisms and coronary heart disease: an evidence-based meta-analysis. Int J Clin Pharmacol Ther 2016; 54: 354-61.

31. Lu JS, Wang H, Yuan FF, et al. Lack of association of tumor necrosis factor superfamily member 4 (TNFSF4) gene polymorphisms (rs3850641 and rs 17568) with coronary heart disease and stroke: A systematic review and metaanalysis. Anatol J Cardiol 2018; 19: 86-93.

32. Weiguang Y, Dalin L, Lidan X, et al. Association of OX40L polymorphisms with sporadic breast cancer in Northeast Chinese Han population. PLoS One 2012; 7: e41277.

33. Croft M. Control of immunity by the TNFR-related molecule OX40 (CD134). Annu Rev Immunol 2010; 28: 57-78. 